\title{
A (in)constitucionalidade da execução das garantias integrantes do Fundo Garantidor de Parcerias Público-privadas
}

\author{
Ariane Catenaci de Lima ${ }^{1}$ \\ Professor Miguel Etinger de Araújo Júnior ${ }^{2}$
}

\section{Resumo}

Análise sintética das regras pertinentes ao contrato administrativo de concessão de serviço público sob a égide da Lei n. 11.079/04. Expõe a instituição e a composição do Fundo Garantidor de Parcerias Público-Privadas - FGP. Aborda a execução do patrimônio do FGP face à sistemática constitucional dos precatórios, em caso de descumprimento contratual pelo parceiro público

Palavras Chave: Contrato de concessão de serviço público; Parcerias públicoprivadas; Fundo garantidor de parcerias; Execução das garantias prestadas pelo parceiro público.

\section{Introdução}

A Constituição Federal de 1988 outorgou à República Federativa do Brasil a titularidade do serviço público com o escopo de concretizar as atividades essenciais aos anseios da coletividade, principalmente, as relativas à prestação de serviço público, sob sua atuação exclusiva ou apenas supervisionada, face ao imperativo de promoção do bem comum (SANTOS, 2004, p. 28).

O Estado, no desempenho de sua função administrativa de prestação de serviços públicos, pode efetuá-lo direta ou indiretamente por transferência de seu exercício a terceiro particular, sob o regime da concessão ou permissão, ou, ainda, por meio de pessoas jurídicas de sua criação.

Contudo, o déficit orçamentário nos cofres públicos constitui cenário desfavorável à atração de investimentos da iniciativa privada dispostos a cooperar na prestação de serviço público.

Graduanda da Universidade Estadual de Londrina. E-mail: arianecatenaci@yahoo.com.br.

O presente artigo originou-se do Trabalho de Conclusão de Curso realizado sob a Orientação do Professor Miguel Etinger de Araújo Júnior, Professor do Curso de Direito da UEL e Mestre em Direito. Área de Concentração: Direitos Fundamentais e Novos Direitos. 
Assim, a Lei das Parcerias Público-Privadas - Lei n. 11.079, de 30 de dezembro de 2004 - Lei das PPP's - introduziu uma nova modalidade de parceria entre a Administração Pública e o particular.

Pretende-se, portanto, analisar as regras pertinentes ao contrato administrativo de concessão de serviço público sob a égide da Lei n. 11.079/04, a instituição e a composição do Fundo Garantidor de Parcerias - FGP, bem como a execução das garantias oferecidas pela Administração Pública ao parceiro privado.

Nesse contexto, aprecia-se a (in)constitucionalidade da execução das garantias que integram o FGP, em caso de descumprimento contratual pelo parceiro público, e a sua compatibilidade com o ordenamento jurídico pátrio.

\section{Considerações gerais sobre a Parceria Público-Privada disciplinada pela Lei $\mathbf{n}$. $11.079 / 04$}

O clássico instituto da concessão de serviço público, depois de reiteradas instabilidades econômicas, revelou-se ineficaz à atração de investimentos vultosos para a execução de serviço público em que a rentabilidade é incerta, acrescido do fato de o concessionário suportar por sua conta e risco o desempenho dessa atividade, cuja contraprestação assegurada pelo Poder Público resume-se, em regra, na cobrança de tarifas dos usuários.

O déficit orçamentário, nos cofres públicos, apresenta-se como cenário desvantajoso a provocar interesse em investidores privados dispostos a colaborar na prestação de serviço público que se apresenta, muitas vezes, indispensável à satisfação das condições mínimas de sobrevivência da coletividade.

Diante dessa conjuntura de estagnação, o legislador ordinário instituiu uma nova modalidade de parceria entre a Administração Pública e o particular, regulamentada pela Lei n. 11.079/04, sob a justificativa de suprir a falta de recursos financeiros, bem como de usufruir a eficiência que, em regra, norteia a atuação da iniciativa privada, a fim de atender as necessidades, preferencialmente, dos setores de segurança pública, de saneamento básico e de infra-estrutura viária ou elétrica (DI PIETRO, 2006).

Marçal Justen Filho (2005, p. 549) conceitua parceria público-privada como: 
contrato organizacional, de longo prazo de duração, por meio do qual se atribui a um sujeito privado o dever de executar obra pública e (ou) prestar serviço público, com ou sem direito à remuneração, por meio da exploração da infra-estrutura, mas mediante uma garantia especial e reforçada prestada pelo Poder Público, utilizável para a obtenção de recursos no mercado financeiro.

Outrossim, Alexandre Santos de Aragão (2006, p. 67-68) conceitua as parcerias público-privadas, sob o aspecto jurídico, como:

contratos de delegação da contratação, ampliação, reforma ou manutenção de determinada infra-estrutura e da gestão da totalidade ou parte das atividades administrativas prestadas por seu intermédio, mediante remuneração de longo prazo arcada total ou parcialmente pelo Estado, fixadas em razão da quantidade ou qualidade das utilidades concretamente propiciadas pelo parceiro privado à Administração Pública ou à população.

Denota-se que a Lei das PPP's (parcerias público-privadas) confere nova moldagem ao contrato de concessão de serviço público, uma vez que se vincula à ampliação, à reforma ou à manutenção de determinada infra-estrutura e à gestão de atividades administrativas, cujos empreendimentos realizam-se mediante o oferecimento de garantia pelo Poder Público.

A Lei n. 11.079/04 institui normas gerais relativas ao procedimento licitatório e à celebração do contrato de parceria público-privada no âmbito da Administração Pública, Direita e Indireta, aplicando-se também às entidades controladas direta ou indiretamente pela União, Estados, Distrito Federal e Municípios.

Ainda, o art. 2o, da Lei n. 11.079/04 contempla que a parceria público-privada é contrato administrativo de concessão, o qual concretiza na modalidade administrativa ou patrocinada. Referido diploma legal, também, alterou a denominação da concessão disciplinada pela Lei n. 8.987/95 para concessão comum.

Constituem, também, parâmetros caracterizadores do contrato de parceria públicoprivada, quais sejam: a execução de obras e serviços públicos de infra-estrutura que envolva investimentos de, no mínimo, $\mathrm{R} \$ \mathbf{2 0 . 0 0 0 . 0 0 0 , 0 0}$ (vinte milhões de reais); período de prestação do serviço não inferior a 05 (cinco) anos; e, não tenha como objeto único o fornecimento de mão-de-obra, o fornecimento e instalação de equipamentos ou a execução de obra pública (art. 2ํㅗ $§ 4 ㅇ ㅡ$, I a III). 
Na fase interna, a Lei das PPP’s enfatiza a incumbência do órgão gestor para eleger os serviços prioritários, regulamentar os procedimentos licitatórios, autorizar a abertura da licitação e aprovar seu edital, bem como apreciar os relatórios de execução dos contratos (art. 14, I a IV).

Compete ao Comitê Gestor das PPP's Federais, preliminarmente à autorização da abertura do procedimento licitatório, analisar a viabilidade financeira, as vantagens sócioeconômicas expostas no estudo técnico elaborado no âmbito do órgão ou entidade responsável pela concepção do projeto, além de verificar a plausibilidade para a assunção de novas despesas pelo Poder Público, consoante o art. 10, I, "a" a "c", da Lei n. 11.079/04, in verbis:

Art. 10. A contratação de parceria público-privada será precedida de licitação na modalidade de concorrência, estando a abertura do processo licitatório condicionada a:

I - autorização da autoridade competente, fundamentada em estudo técnico que demonstre:

a) a conveniência e a oportunidade da contratação, mediante identificação das razões que justifiquem a opção pela forma de parceria público-privada;

b) que as despesas criadas ou aumentadas não afetarão as metas fiscais previstas no Anexo referido no §1어 do art. 4ㅇ da Lei Complementar no 101, de 4 de maio de 2000, devendo seus efeitos financeiros, nos períodos seguintes, ser compensados pelo aumento permanente de receita ou pela redução permanente de despesa; e c) quando for o caso, conforme as normas editadas na forma do art. 25 desta Lei, a observância dos limites e condições decorrentes da aplicação dos arts. 29, 30 e 32 da Lei Complementar no 101, de 4 de maio de 2000, pelas obrigações contraídas pela Administração Pública relativas ao objeto do contrato; $[\ldots]$

Ao órgão gestor, cabe, inclusive, aferir o impacto orçamentário-financeiro nos exercícios subseqüentes acometidos pela vigência do contrato de parceria público-privada, verificar a previsão do objeto do contrato no plano plurianual, evitando a criação de despesas que comprometam as metas fiscais da Lei de Diretrizes Orçamentárias e, por conseguinte, afrontem as regras instituídas pela Lei de Responsabilidade Fiscal (art. 10, II a V, da Lei n. 11.079/04).

Concluída a apreciação do estudo técnico do projeto de parceria, o órgão gestor aprova-o ou não, apresentando as razões que autorizam ou não a execução do objeto do contrato sob o regime de parceria público-privada, na forma administrativa ou patrocinada. 
A concessão administrativa é contrato de prestação serviços públicos de que a Administração Pública seja a usuária direta ou indireta, ainda que envolva execução de obra ou fornecimento e instalação de bens, desde que o seu objeto se restrinja ao fornecimento de mão-de-obra, ao fornecimento de equipamentos ou a execução de obra pública (art. 2으, $\S 2$ o c/c §4으, III, da Lei n. 11.079/04).

Alexandre Santos de Aragão (2006, p. 66) assevera que a contraprestação pecuniária devida pelo parceiro público ao concessionário administrativo vincula-se à quantidade e/ou qualidade da atividade disponibilizada à Administração Pública ou aos usuários, justificando a repartição objetiva dos riscos do empreendimento entre as partes (arts. 4으, VI, 5으, III, e 7으, da Lei n. 11.079/04).

A concessão patrocinada refere-se aos contratos de concessão de serviços públicos ou de obras públicas regidos pela Lei n. 8.987/95, em que a recuperação dos investimentos pode-se efetivar pela cobrança de tarifa dos usuários associada ao pagamento de contraprestação pecuniária do parceiro público (art. 2ํ, §1으, da Lei n. 11.079/04).

A contraprestação da Administração Pública realiza-se depois de confirmada a disponibilidade e a qualidade do serviço objeto do contrato de parceria público-privada, podendo, ainda, segundo a sua faculdade, remunerar, tão-somente a parcela fruível do serviço contratado (arts. 60 e 70 , da Lei n. 11.079/04).

Com efeito, a contraprestação pecuniária efetuada pela Administração Pública revela-se como mecanismo atrativo de investimentos privados, a fim de equacionar a insuficiência de recursos financeiros públicos para a prestação de serviços relacionados às atividades de infra-estrutura de que, atualmente, o Estado brasileiro é carecedor.

O contrato de parceria público-privada oportuniza, na fase de elaboração das cláusulas contratuais, às partes a partilha de riscos que envolvem a execução da atividade objeto da avença, bem como especificarem a quem compete suportá-los, inclusive os riscos relativos ao caso fortuito, à força maior e à álea econômica extraordinária (arts. 4으, VI e 5oㅡ, III, da Lei n. 11.079/04).

Nesse sentido, assevera Aline Paola Correa Braga Câmara de Almeida (2006, pp. 248 e 268) que:

Deve o Poder Público, no momento da formatação da contratação, arrolar todas as espécies de risco em potencial, levando em consideração a realidade de mercado e 
do objeto contratual, além das expectativas do parceiro privado. Após, deve verificar quais deles poderão ser assumidos integralmente pelas partes - uma vez causados pelas mesmas - e quais são os que deverão ser compartilhados e qual a proporção respectiva.

[...]

Não resta dúvida que a nova legislação representa um avanço em relação à Lei $n$. 8.666/93 e à própria Lei n. 8.987/95, mormente porque se inicia um processo de análise dos riscos à luz da realidade de cada contrato e a idéia de que, uma vez mapeados e compartilhados, a tendência é que os preços pagos pelo parceiro público sejam reduzidos, seguindo uma lógica econômica de que quanto menor o risco menor será o valor a ser desembolsado.

Destarte, a prévia repartição dos riscos fixa a responsabilidade de cada parte ao definir os eventos negativos que lhes poderão ser dirigidos. Além disso, a eficiente gestão dos riscos protege o empreendimento, uma vez que impõe uma atuação diligente ao seu potencialmente causador, minimizando a ocorrência de eventos danosos (ALMEIDA, 2006, p. 243).

E, o compartilhamento dos riscos contribui para otimizar a eficiência e a fiscalização da execução do contrato, bem como reduzir os seus custos, favorecendo a elaboração de propostas com margem de lucro menor, já que os contratantes estão cientes de seus encargos (ALMEIDA, 2006, p. 243).

A Lei n. 11.079/04, também, prevê o compartilhamento com a Administração Pública de ganhos econômicos efetivos do parceiro privado decorrentes da redução do risco de créditos dos financiamentos utilizados pelo parceiro privado (art. 5으, IX).

No que concerne à prestação de garantias pela Administração Pública, a Lei n. 11.079/04 em seu art. 8o enumera quais são:

Art. 8ㅇ As obrigações pecuniárias contraídas pela Administração Pública em contrato de parceria público-privada poderão ser garantidas mediante:

I - vinculação de receitas, observado o disposto no inciso IV do art. 167 da Constituição Federal;

II - instituição ou utilização de fundos especiais previstos em lei;

III - contratação de seguro-garantia com as companhias seguradoras que não sejam controladas pelo Poder Público;

IV - garantia prestada por organismos internacionais ou instituições financeiras que não sejam controladas pelo Poder Público;

$\mathrm{V}$ - garantias prestadas por fundo garantidor ou empresa estatal criada para essa finalidade;

VI - outros mecanismos admitidos em lei. 
Portanto, constatada a inadimplência da Administração Pública nos contratos de parceria público-privada, o parceiro privado tem a faculdade de executar as aludidas garantias, dentre elas as prestadas pelo fundo garantidor. A Lei n. 11.079/04 delineou as regras gerais do FGP que a seguir serão abordadas.

\section{A Instituição do Fundo Garantidor de Parcerias e sua composição patrimonial}

O FGP (fundo garantidor de parcerias) instituído com o escopo de prestar garantia de pagamento de obrigações pecuniárias assumidas pelo parceiro público, na esfera federal, objetiva suscitar interesse na iniciativa privada em implementar investimentos vultosos e, conseqüentemente, em colaborar com o Poder Público, em específico, com a União, autarquias e fundações públicas federais quanto à prestação de serviço público à coletividade.

Discute-se acerca da constitucionalidade da instituição do FGP pela Lei n. 11.079/04 - lei ordinária - face à redação do art. 165, §9ㅇ, II, da CF, segundo a qual cabe a lei complementar estabelecer normas de gestão financeira e patrimonial da administração direta e indireta, bem como condições para a instituição e funcionamento dos fundos.

Todavia, verifica-se descabida a supracitada alegação, tendo em vista que o legislador constituinte não condicionou à lei complementar a instituição de fundo, mas sim a regulamentação das condições de sua instituição e de seu funcionamento.

Por oportuno, cumpre registrar que a Lei n. 4.320/64, recepcionada pela Constituição Federal de 1988 como lei complementar, em seus arts. 71 a 74, atende aos preceitos do art. 165, §9o , II, da CF, prescrevendo apenas que lei e, portanto, que compete à lei ordinária disciplinar a instituição de fundo pode, inclusive, estabelecer normas peculiares de controle, prestação e tomada de contas.

$E$, ainda, que se entenda que a instituição de fundo depende de lei complementar, com fulcro no art. 165, § 9o, II, da CF, há que se ressaltar que a aludida exigência refere-se a fundos especiais, e não a qualquer tipo de fundo, pois visa limitar a utilização daqueles fundos, também denominados de orçamentários, pelos entes públicos, evitando a violação ao princípio da unidade finalística do orçamento (BRAGA, 2006, p. 235).

Fabiana Andrada do Amaral Rudge Braga (2006, p. 235) tece os seguintes comentários sobre o que entende ser um fundo: 
[...] a reunião de bens e direitos, formando um patrimônio, que se propõe a uma específica destinação, a ser gerido por um administrador. Mas o que difere os diversos tipos de fundos é a finalidade de cada qual se propõe a concretizar e em razão da qual os seus investidores decidem por realizar a dotação de bens. No caso do fundo do mercado financeiro, a finalidade é o investimento, com parceiros que se unem em condomínio para uma aplicação conjunta dos recursos, unindo esforços financeiros e maximizando os ganhos. No fundo especial, ou orçamentário, a finalidade é a vinculação de determinadas receitas, para reunião no fundo, com vistas à execução de um determinado objeto. Através dele, o Poder Público executa políticas públicas, que se viabilizam através das receitas públicas vinculadas ao objeto específico de cada fundo.

Acrescenta a doutrinadora (BRAGA, 2006, p. 236) que o FGP não se confunde com o fundo de mercado financeiro ou com o fundo especial, uma vez que não objetiva o investimento de recursos, nem a execução de um objeto por meio de vinculação de receitas, já que ele:

[...] pressupõe a transferência (disposição, alienação) de determinados bens e direitos do erário público a um patrimônio autônomo e privado - respeitadas, naturalmente, as normas de direito financeiro, os limites orçamentários e da Lei de Responsabilidade Fiscal -, para servir, no limite das contas integralizadas, de garantia à execução de determinadas, dívidas líquidas e certas, do Poder Público em parceria com a iniciativa privada. No FGP, a finalidade é a prestação de garantia de obrigações contraídas pelo Poder Público (BRAGA, 2006, p. 236).

Conclui-se, assim, ser infundada a inconstitucionalidade quanto à instituição do FGP pela Lei n. 11.079/04, tendo em vista que a mesma não se submete à regra prescrita no art. $165, \S 90$, II, da CF.

A Lei das PPP's define como privada a natureza do FGP, o qual se constitui de patrimônio próprio distinto do patrimônio de seus cotistas, ou seja, de bens e direitos realizados pelos cotistas por meio de integralização de cotas e de rendimentos auferidos com sua administração, conferindo, ainda, a prerrogativa de sujeito de direitos e obrigações próprias (art. 16, §§1으 e 2으, Lei n. 11.079/04).

A integralização das cotas pode ser efetuada por dinheiro, títulos da dívida pública, bens imóveis dominicais, bens móveis, ações de sociedade de economia mista excedentes à manutenção de seu controle pela União, ou outros direitos com valor patrimonial. Esse procedimento concretiza-se por proposta do Ministro da Fazenda mediante prévia avaliação e autorização específica do Presidente da República, independentemente de licitação (art. 16, §§4으 e 6으, Lei n. 11.079/04). 
Determina a Lei n. 11.079/04 que os bens públicos de uso especial e de uso comum tão-somente integram o patrimônio do Fundo sob a condição de desafetação individualizada (art. 16, §7으), consoante prescreve o art. 100, do Código Civil: "Os bens públicos de uso comum do povo e os de uso especial são inalienáveis, enquanto conservarem a sua qualificação, na forma que a lei determinar".

A princípio, são bens públicos patrimoniais indisponíveis, sejam bens móveis ou imóveis, os bens de uso especial ou de uso comum suscetíveis de avaliação patrimonial. Todavia, tais bens públicos são disponíveis, desde que não estejam afetados a certa finalidade pública, podendo ser alienados na forma e nas condições que a lei estabelecer.

Os bens de uso comum do povo e os bens de uso especial, enquanto destinados, respectivamente, ao uso geral do povo e a fins administrativos, não são suscetíveis de alienação. Por outro lado, se tais bens venham a perder sua finalidade pública específica, convertem-se em bens dominicais e, portanto, podem ser alienados, desde que observadas às exigências legais, consoante prescreve o art. 101, do Código Civil.

Logo, afasta-se a discussão de possível fraude ao regime de bens públicos face à exposição supra que demonstra a legitimidade do art. 16, §7으, da Lei n. 11.079/04, e sua compatibilidade com o ordenamento jurídico, embora seja a inalienabilidade uma das características dos bens públicos.

Salienta-se que os bens públicos desafetados destinam-se a viabilizar outra finalidade pública ao permitir à formalização de contratos de parceria público-privadas e, conseqüentemente, a prestação de serviços públicos à coletividade.

Todavia, a desafetação de tais bens corresponde à subtração do caráter de inalienabilidade e de impenhorabilidade, motivo pelo qual somente mediante justificativa plausível acerca da impossibilidade de realização de determinado serviço público sob contrato de concessão, eis que em caso de inadimplemento do parceiro público esses bens serão definitivamente subtraídos do patrimônio público.

Nesse contexto, Fabiana Andrada do Amaral Rudge Braga (2006, p. 224) manifestase sobre a faculdade de disponibilização dos bens públicos, preconizando que:

O Fundo Garantidor das PPPs obedece às seguintes diretrizes básicas: a União Federal, na forma da Lei 11.709/2004, e os demais entes da federação, seguindo o que dispuser a legislação própria, poderão realizar a disposição de bens públicos, que sairão do patrimônio público, passando a integrar patrimônio de natureza 
privada, consubstanciada no FGP, que, mediante a gestão da respectiva instituição financeira controladora, servirá, até o limite do seu patrimônio integralizado pelos cotistas, para respaldar as garantias oferecidas pelo Poder Público nos contratos de parceria com a iniciativa privada.

Vislumbra-se que a transformação da natureza pública para privada dos bens de uso especial e de uso comum vincula-se à necessidade de a União, parceiro público federal, ratificar o seu compromisso de oferecer garantias hábeis a provocar interesse no parceiro privado e, por conseguinte, cooperar com o parceiro público na concretização de políticas sociais que exigem investimentos iniciais vultosos, nos termos do art. $2 \stackrel{2}{ }$, da Lei n. 11.079/04.

O FGP, instrumento direcionado a assegurar, precipuamente, o cumprimento das obrigações pecuniárias resultantes da celebração do contrato de parceria público-privada, compõe-se de garantias, que são prestadas à proporção do valor da participação de cada cotista, disciplinadas pelo art. 18, Lei n. 11.079/04.

O elenco de garantias trazidas pela Lei n. 11.079/04 apresenta-se como reforço necessário à atração de recursos da iniciativa privada. Essa postura se justifica em virtude de investimentos vultosos efetuados pelos particulares, de sua amortização em longo prazo e da insegurança de retorno do capital investido.

O FGP responde por suas obrigações com os bens e direitos integrantes de seu patrimônio, não respondendo os seus cotistas por qualquer obrigação do FGP, exceto pela integralização das cotas que subscreverem (art. 16, §5으, Lei n. 11.079/04).

A exoneração das garantias, em caso de inadimplemento contratual pelo Poder Público, pode efetuar-se proporcionalmente à quitação pelo parceiro público de cada parcela de débito garantido pelo FGP ou integralmente, quando da dissolução do FGP, mediante deliberação pela assembléia dos cotistas, com prévia quitação da totalidade dos débitos garantidos ou liberação das garantias pelos credores. Em seguida, o patrimônio do FGP dissolvido deve ser rateado, considerando a situação patrimonial à data da dissolução, entre seus contistas (arts. 18, §3ㅇ, e 20, da Lei n. 11.079/04).

O FGP sub-roga-se nos direitos do parceiro privado quando da quitação de débito do parceiro público inadimplemente (art. 18, §6으, da Lei n. 11.079/04).

Conclui-se que o FGP constitui instrumento inovador na ordem jurídica por suas obrigações estarem adstritas às garantias oferecidas em decorrência da celebração de 
contratos regidos pela Lei n. 11.079/04. Cumpre, então, averiguar o procedimento de execução de seu patrimônio.

\section{A execução do Patrimônio do Fundo Garantidor de parcerias público-privadas versus a sistemática constitucional dos precatórios}

A possibilidade de o Poder Público prestar garantias nas suas contratações públicas em favor do parceiro privado apresenta-se como situação inovadora no nosso ordenamento jurídico com o advento da Lei n. 11.079/04, eis que a prestação de garantias restringia-se ao contratado em prol da Administração Pública nas contratações administrativas disciplinadas pelas Leis n. 8.666/93 e 8.987/95.

Nesse novo cenário, se verificado o inadimplemento do Poder Público, o FGP responde, até os limites da dívida garantida e nas condições impostas por lei, com bens e direitos integrantes de seu patrimônio, que podem ser objeto de constrição judicial e alienação para cumprir as obrigações garantidas pelo ente público quando da execução dessas (art. 18, §7으, da Lei n. 11.079/04).

Exige-se para qualquer espécie de execução a existência de título líquido, certo e exigível, conforme dispõe o art. 586, do Código de Processo Civil (CPC). A liquidez diz respeito à determinação do valor da prestação em relação a sua quantificação, qualidade, natureza e espécie; a certeza consubstancia-se na ausência de controvérsia quanto à sua existência; e a exigibilidade concerne ao vencimento da dívida, significa dizer que deve independer de termo, condição ou qualquer outra limitação (THEODORO JÚNIOR, 2003,

pp. 32-33).

No caso do FGP, o título executivo extrajudicial (art. 585 do CPC) materializa-se com o oferecimento de garantias, reais ou fidejussórias, em favor do parceiro privado, nos termos da Lei $n .11 .079 / 04$.

O Código de Processo Civil estabelece, como requisito de admissibilidade de execução forçada, a concorrência de dois pressupostos indispensáveis, quais sejam: o inadimplemento do devedor e título executivo, judicial ou extrajudicial (arts. 580 c/c 583, do CPC) (THEODORO JÚNIOR, 2003, p. 340).

Destarte, a execução das referidas garantias previstas na Lei n.11.079/04 pressupõe a ocorrência concomitante do inadimplemento do parceiro público e dos requisitos de 
liquidez, certeza e exigibilidade do título executivo extrajudicial emitido, e, se não satisfeita pela via administrativa, pode-se recorrer à via judicial para executar o patrimônio do FGP.

A Lei n. 11.079/04 prevê, ainda, condicionantes exclusivas nos §§4ㅇ e 5으 do art. 18 para a execução da garantia em face do FGP. O §4으 determina que, na hipótese de título, além de líquido, certo e exigível, aceito e não pago pelo parceiro público inadimplente, a garantia oferecida com o patrimônio do FGP apenas pode ser acionada pelo parceiro privado a partir do 45 (quadragésimo quinto) dia do seu vencimento. Já o §5ㅇa autoriza o parceiro privado acionar a garantia referente a débitos contra o FGP constantes de faturas emitidas e não aceitas pelo parceiro público, e nem expressamente rejeitadas por ato motivado, tãosomente depois de 90 (noventa) dias de seu vencimento.

Fabiana Andrada do Amaral Rudge Braga (2006, p. 233) esclarece que o "aceite" mencionado pela Lei n. 11.079/04 concerne ao "empenho", que correspondente à primeira fase de realização da despesa pública, haja vista que, segundo a redação do art. 58, da Lei n. 4.320/64, empenho de despesa é ato emanado de autoridade competente que cria para o Estado obrigação de pagamento pendente ou não de implemento de condição. Por conseguinte, o Poder Público reconhece obrigação de pagamento após o empenho e a expedição de sua respectiva nota.

Acrescenta a jurista que na hipótese de o parceiro não aceitar o título e expressamente rejeitar, por ato motivado, o reconhecimento da dívida, adotando-se uma interpretação sistemática entre os $\S \S 4$ e e 5o do art. 18, da Lei n. 11.079/04 e à luz do princípio da razoabilidade, extrai-se que o não aceite do título previsto no aludido §5o, em regra, deve fundar-se no não implemento das condições de liquidez e certeza do crédito e exigibilidade do título (BRAGA, 2006, p. 233).

A ausência desses requisitos imprescindíveis à constituição de título executivo implica nulidade de eventual execução instaurada, a qual pode ser impugnada por meio de objeção de pré-executividade ou de embargos à execução, com base nos arts. 741 e 745, do CPC. Logo, o acolhimento das matérias previstas em tais dispositivos impossibilita a execução de garantia resguardada pelo patrimônio do FGP.

Entretanto, a apresentação tempestiva do aludido ato motivado não impede, o início da execução da garantia por parte do parceiro privado, tendo em vista que tal matéria 
controvertida pode ser objeto de impugnação no processo executivo pelos instrumentos supracitados (BRAGA, 2006, p. 233).

O procedimento de execução das garantias em face do FGP rege-se pelos dispositivos do Código de Processo Civil relativos à execução comum de título executivo extrajudicial, haja vista que, como já esclarecido no item anterior deste capítulo, o patrimônio do FGP é próprio, de natureza privada, e, completamente, distinto do patrimônio de seus cotistas.

Alega-se violação da sistemática constitucional do precatório (art. 100, da CF) e, por conseqüência, ofensa aos princípios orçamentários constitucionais quando da realização de despesas públicas, eis que não há observância ao procedimento especial de execução contra a Fazenda Pública (arts. 730 e 731, do CPC), implicando, assim, a criação de classe privilegiada de credores do Poder Público.

O aparente desrespeito aos princípios orçamentários constitucionais não persiste, já que a Lei n. 11.079/2004 determina que a contratação sob a sua égide deva condicionar-se à comprovação, por estudo técnico, que as despesas resultantes dessa modalidade de contrato não afetarão as metas de resultados fiscais previstas no Anexo mencionado na Lei Complementar n. 101/00 (art. 4으, §1ํ), além de prever a elaboração de estimativa de impacto orçamentário-financeiro nos exercícios em que vigorará o contrato de parceria público-privada (art. 10).

Salienta-se, por oportuno, que por inexistir bens indisponíveis no FGP não se vislumbra realização de despesa pública que imponha previsão no orçamento público (BRAGA, 2006, p. 240).

A execução contra a Fazenda Pública, nos termos dos arts. 730 e 731, do CPC, procede-se mediante requisição, pelo juiz, de pagamento por intermédio do Presidente do Tribunal competente, que a dirige à Fazenda Pública executada, quando não houver oposição de embargos, ou após a rejeição desses. Essa requisição é conhecida como expedição de precatório e o seu pagamento faz-se pela ordem de apresentação do mesmo e à conta do respectivo crédito.

A Constituição Federal, ao regulamentar o sistema de precatórios em seu art. 100, determina ser obrigatória a inclusão, no orçamento das entidades de direito público, de verba necessária ao pagamento de seus débitos decorrentes de sentenças transitadas em 
julgado, constantes de precatórios judiciais, apresentados até 10 de julho, fazendo-se o pagamento até o final do exercício seguinte, quando terão seus valores atualizados monetariamente.

Carlos Ari Sundfeld (2006), jurista participante da elaboração da Lei das PPP's, em entrevista concedida à Revista Consultor Jurídico, defende a não sujeição do parceiro privado à sistemática do precatório, sustentando que:

\begin{abstract}
Não há nenhuma inconstitucionalidade no sistema que cria credores com privilégios. Em primeiro lugar, porque se trata de oferecer garantia para quem não é obrigado a fazer investimento. O país quer ou não quer crescer? Se quiser, precisa dar garantia. É isso, simples assim. Então, dizer que a União não pode dar garantia, que o sistema todo de proteção de créditos tem de ter a execução prevista no artigo 100 da Constituição me parece exagerado.
\end{abstract}

Cumpre esclarecer que o Código de Processo Civil confere procedimento específico para a execução por quantia certa em face da Fazenda Pública não se dá em virtude da dívida que se pretende quitar, mas, como, regra, da característica de impenhorabilidade de seus bens, que os impossibilitam serem executados nos moldes comuns passando pelas fases de penhora e expropriação (THEODORO JÚNIOR, 2003, p. 249).

Denota-se, assim, que não procede a aludida afronta à sistemática constitucional dos precatórios resultante de inobservância aos arts. 730 e 731, do CPC, por ausência de subsunção da hipótese à norma, visto que o FGP é patrimônio autônomo e privado, embora assegure a concretização de interesse público (BRAGA, 2006, p. 227).

Convém destacar que as obrigações não protegidas pelas garantias oferecidas com o patrimônio do FGP e, as não asseguradas pelo FGP, em razão de falta de liquidez deste, embora constante de título executivo extrajudicial emitido nos termos da Lei n. 11.079/04, devem ser diretamente executadas em face do patrimônio do parceiro público, sujeitandose, ao processo executivo disciplinado pelos arts. 730 e 731, do CPC e, conseqüentemente, à sistemática dos precatórios (BRAGA, 2006, p. 239).

A propósito, Fabiana Andrada do Amaral Rudge Braga (2006, p. 240) sustenta que:

[...] a presunção é de que a Administração Pública honrará com suas obrigações administrativa e amigavelmente e não de que a satisfação somente será alcançada pela via judicial e, como conseqüência, por precatório. Do contrário, seria de presumir que qualquer pagamento amigável de obrigações contraídas pela Administração Pública estaria, de forma indireta, violando a ordem dos precatórios, 
o que é um absurdo. Igualmente legítimas, por outro lado, são as iniciativas do Estado no sentido tornar mais atrativos os negócios firmados com parceiros privados, mediante o oferecimento de garantias à execução de suas obrigações contratuais, seja em face do seu patrimônio (execução de título extrajudicial que deverá seguir o procedimento previsto nos arts. 730 e 731 do $(P C)$, seja através de garantia oferecida por terceiro, detentores de patrimônio autônomo e privado, como no caso do FGP, e desde que, é claro, os princípios da igualdade e da impessoalidade tenham sido observados quando do procedimento licitatório.

Portanto, é legítima a atuação do Poder Público em busca de mecanismo hábil a obter investimentos vultosos da iniciativa privada com o escopo de oferecer a prestação de serviços públicos essenciais à coletividade e, por conseguinte, viabilizar a promoção do bemestar social, pois resta demonstrada sua plena conformidade com o ordenamento jurídico pátrio.

\section{Considerações finais}

Ao Estado impende, como reflexo histórico-político do grupo social que o integra e o legitima, concretizar os seus objetivos fundamentais elencados na Constituição Federal de 1988, entre eles, o de reduzir as desigualdades sociais, eis que a prestação de tais serviços visa satisfazer as necessidades essenciais à dignidade da pessoa humana.

A Lei das PPP's traz diretrizes inovadoras com o propósito de colaborar com o Estado na consecução de seu mister constitucional de prestar serviço público, prevendo o compartilhamento de riscos entre as partes, bem como a prestação pela Administração Pública de garantia pelas obrigações pecuniárias assumidas pelo parceiro público por meio do patrimônio que compõe o FGP.

O FGP, instituído com o escopo de garantir o pagamento de obrigações pecuniárias contraídas pelo parceiro público, objetiva suscitar interesse na iniciativa privada em investir recursos financeiros e, conseqüentemente, colaborar com o Poder Público, em específico, com a União, autarquias e fundações públicas federais quanto à prestação de serviço público à coletividade.

O patrimônio do FGP é autônomo, de natureza privada, e, completamente, diverso do patrimônio de seus cotistas. A execução do patrimônio do FGP pressupõe título executivo extrajudicial líquido, certo e exigível, que se materializa com o oferecimento de garantias, reais ou fidejussórias, em favor do parceiro privado, nos termos da Lei n. 11.079/04. 
O procedimento de execução de tais garantias em face do FGP rege-se pelos dispositivos do Código de Processo Civil referentes à execução comum de título executivo extrajudicial e não pelo procedimento de execução por quantia certa contra a Fazenda Pública.

A sistemática constitucional do precatório está adstrita ao procedimento especial de execução contra a Fazenda Pública (arts. 730 e 731, do CPC) e, por conseguinte, a execução em face do FGP não foi violada por ausência total de subsunção da hipótese à norma.

Contudo, as obrigações não protegidas pelas garantias advindas do contrato de parcerias público-privadas, bem como aquelas que não podem ser saldadas face à iliquidez do FGP, são diretamente executadas em face do patrimônio do parceiro público submetemse, portanto, ao processo executivo disciplinado pelos arts. 730 e 731, do CPC e, conseqüentemente, à sistemática dos precatórios.

Considerando o histórico brasileiro na tentativa em reduzir o déficit público associado à responsabilidade do Estado em viabilizar obras e serviços de infra-estrutura, a atuação do Poder Público por meio de contrato de parceria público-privada constitui instrumento legítimo a capturar investimento privado, bem como usufruir deste a sua competência de gestão na realização das políticas públicas.

\section{Referências}

ALMEIDA, Aline Paola Correa Braga Camara de. Compartilhamento de riscos nas parcerias público-privadas. Revista de Direito da Associação dos Procuradores do Novo Estado do Rio de Janeiro, Rio de Janeiro, v.17, p.241-268, 2006.

ARAGÃO, Alexandre Santos. As parcerias público-privadas - PPP's no direito positivo brasileiro. Revista de Direito da Associação dos Procuradores do Novo Estado do Rio de Janeiro, Rio de Janeiro, v.17, p. 51-90, 2006.

BINENBOJM, Gustavo. As parcerias público-privadas (PPP's e a Constituição). Revista de Direito da Associação dos Procuradores do Novo Estado do Rio de Janeiro, Rio de Janeiro v. 17, p.91-107, 2006.

BRAGA, Fabiana Andrada do Amaral Rudge. PPP: o fundo garantidor, a execução das garantias e a compatibilidade o sistema constitucional dos precatórios. Revista de Direito da 
Associação dos Procuradores do Novo Estado do Rio de Janeiro, Rio de Janeiro, v.17, p.223240, 2006.

DI PIETRO, Maria Sylvia Zanella. Reflexões sobre as Parcerias Público-Privadas. Carta Forense. Disponível em: <http://www.azevedosette.com.br/ppp/artigos/reflexoes.html>. Acesso em: 08 out. 2006.

JUSTEN FILHO, Marçal. Teoria geral das concessões de serviço público. São Paulo: Dialética, 2003.

JUSTEN FILHO, Marçal. Curso de direito administrativo. São Paulo: Saraiva, 2005.

SANTOS, José Anacleto Abduch. Contratos de concessão de serviço público: equilíbrio econômico-financeiro. 1. ed. Curitiba: Juruá, 2004.

SUNDFELD, Calos Ari. Receita para crescer: juízes precisam observar regras e não ceder a clamores. Revista Consultor Jurídico. Disponível em:

<http://conjur.estadao.com.br/static/text/40147,1>. Acesso em: 08 out. 2006.

THEODORO JÚNIOR, Humberto. Curso de direito processual civil. 34. ed. Rio de Janeiro: Forense, 2003. v. 2. 
